\title{
Impactos causados em cursos d’água por aterros controlados desativados no Município de São Paulo, Sudeste do Brasil
}

\author{
Beatriz Paulino Rosa ${ }^{1}$, Bruno Cesar de Lima Paula ${ }^{2}$, Estefanie Soares \\ do Amaral Coleone ${ }^{1}$, Fábio Campos ${ }^{1 * *}$
}

${ }^{1}$ Curso de Gestão Ambiental. Escola de Artes e Ciências Humanas (EACH). Universidade de São Paulo (USP). Rua Arlindo Béttio, 1000. Ermelindo Matarazo. São Paulo-SP (CEP 03828-000).*E-mail: fcampos@usp.br.

${ }^{2}$ Curso de Sistema de Informação. Escola de Artes e Ciências Humanas (EACH). Universidade de São Paulo (USP). Rua Arlindo Béttio, 1000. Ermelindo Matarazo, São Paulo-SP (CEP 03828-000).

Resumo. A geração de resíduos sólidos é um problema que afeta as grandes metrópoles há muito tempo. A falta de espaço físico, aliado a não aplicação de técnicas corretas de tratamento, conferem a essa atividade status de grande potencial poluidor. Dos problemas ambientais mais comuns associados à disposição final de resíduos sólidos, encontra-se a liberação do lixiviado, um líquido resultante da decomposição do lixo, cuja composição é altamente poluente. No Brasil, em especial atenção ao Município de São Paulo, durante muito tempo foram adotadas práticas inadequadas de tratamento do lixo, como principalmente os aterros controlados, os quais não possuem mecanismos de coleta do lixiviado, permitindo sua infiltração e consequente contaminação de corpos d'água superficiais ou subterrâneos. No presente trabalho, realizou-se o levantamento dos aterros desativados no Município de São Paulo através de georreferenciamento, utilizando o software QGis. Após a análise dos resultados, identificou-se a presença de cursos d'água próximos em até $200 \mathrm{~m}$ dos aterros, configurando eventuais riscos desses corpos d'água terem ou estarem recebendo a contribuição de lixiviado advindo desses aterros desativados. Isto posto, é possível concluir que, por mais que o Município de São Paulo esteja empenhado em adequar-se frente às novas políticas públicas de disposição de resíduos sólidos, há um passivo histórico que persiste e que pode ser objeto de perturbação da qualidade dos corpos d'água já tão impactados e deteriorados, demandado, portanto, ações de monitoramento e recuperação ambiental dos cursos d'água eventualmente impactados por essa prática.

Palavras-chave: Aterros desativados; Lixiviado de aterro sanitário; Poluição hídrica; Saneamento.

Abstract. Impacts on water courses for disabled landfills in the
municipality of São Paulo, Southeast Brazil. Solid waste generation
is problem that has been affecting large cities for a long time, both
lack of physical space and non-application of correct treatment
techniques causes this activity to be a potential polluter. Among the
most common environmental problems related to final waste disposal,

Recebido:

$10 / 01 / 2017$

Aceito:

15/06/2017

Publicado:

30/06/2017

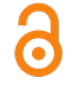

Acesso Aberto

Artigo completo

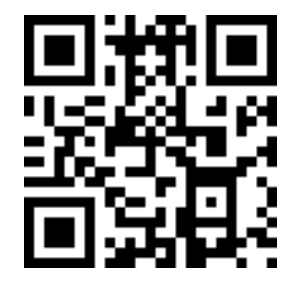

ORCID

다 0000-0002-8192-789X

Beatriz Paulino Rosa

(1) 0000-0002-5834-045X

Bruno Cesar de Lima

Paula

(1) 0000-0003-2891-4632

Estefanie Soares do

Amaral Coleone

Do 0000-0002-8117-789X

Fábio Campos 
there is the leachate release, a result of garbage degradation, whose composition is highly environmentally harmful. In Brazil, with special attention to Municipality of São Paulo, for a long time were adopted inappropriate techniques for waste treatment, as mainly controlled landfill, which does not have mechanisms for leachate collection, allowing it to infiltrate and consequent contamination of surface and underground bodies of water. In the present work, is made a survey of deactivated controlled landfill sites in the Municipality of São Paulo through geo-referencing, using the software QGis. After the results analysis, nearby watercourses were identified up to $200 \mathrm{~m}$ from the landfill sites, setting up eventual risks of these bodies of water had receive or be receiving a leachate from these deactivated landfill sites. That said, it can be concluded that despite the efforts of the Municipality of São Paulo to fit the new public policies for solid waste disposal, there is a history that persists and can affect the quality of bodies of water which are already polluted in this city, demanding environmental monitoring and recovering of watercourses harmed by this technique.

Keywords: Disabled landfills; Landfill leachate; Water pollution; Sanitation.

\section{Introdução}

No período de 2003 a 2014 a geração de lixo no Brasil apresentou um aumento de $29 \%$, segundo o levantamento divulgado pela Associação Brasileira de Empresas de Limpeza Pública e Resíduos Especiais (ABRELPE). A taxa é cinco vezes maior que o crescimento populacional no período, que foi de $6 \%$ (ABRELPE, 2014).

A Região Metropolitana do Município de São Paulo, com seus 19,7 milhões de habitantes, é a maior do Brasil, e um dos maiores aglomerados urbanos do mundo, sendo responsável pela produção estimada de $16.233 \mathrm{t}$ de resíduos sólidos por dia, o correspondente a quase $10 \%$ do coletado no país (Besen, 2011).

De acordo com Autoridade Municipal de Limpeza Urbana (AMLURB), da Prefeitura de São Paulo, o município produz $20 \mathrm{mil} \mathrm{t/dia} \mathrm{de} \mathrm{resíduos} \mathrm{sólidos,}$ sendo $12 \mathrm{mil} \mathrm{t} /$ dia somente de lixo residencial. Atualmente, duas concessionárias executam os trabalhos de coleta de resíduos domiciliares, seletivos e hospitalares, a Ecourbis Ambiental S.A., que atua na Região Sudeste do município e a Logística Ambiental de São Paulo (Loga), na região noroeste (São Paulo, 2016).

Apesar das inúmeras técnicas de destinação final dos resíduos urbanos, a mais empregada é o aterramento, muito em função do menor custo de implantação e operação, que apresentam em relação a outras opções tecnológicas (Cameron et al., 1997). Entretanto, quer seja em função da ineficácia dos aterros, sobretudo àqueles projetados e operados de maneira irregular, em minimizar os impactos negativos que podem causar ao ambiente, ou devido a sua localização não observando as limitações legais, fazem com que esses locais tenham recebido uma especial atenção, por parte das autoridades e órgãos ligados ao meio ambiente, nos últimos anos (Mondelli et al., 2016; Samuel-Rosa et al., 2012).

Dentre os problemas advindos da má operação dos aterros sanitários, merece maior atenção a incapacidade de coletar os líquidos gerados pela decomposição do lixo (lixiviado), permitindo que ele atinja o solo e, eventualmente, corpos d'água superficiais e subterrâneos. Tal lixiviado, em função de sua composição, apresenta um alto poder poluidor a esses ambientes. 
Em se tratando da contaminação das águas subterrâneas, há a agravante de que ela só é detectada vários anos após o início do processo, pois o movimento dos poluentes pelo solo costuma ser lento (Guimarães, 2000).

Países desenvolvidos contam com programas de monitoramento da qualidade da água e do solo em áreas contaminadas ou em ameaça, algo incipiente na realidade brasileira (Mondelli et al., 2016).

Neste sentido, o presente trabalho teve por objetivo, realizar o georreferenciamento no Município de São Paulo de aterros desativados, buscando identificar a presença de corpos d'água em seu entorno que possam ser objetos de uma eventual contaminação, sobretudo, em função da liberação de seu lixiviado. Buscou-se, com isso, avaliar a necessidade da adoção de programas de monitoramento ou mesmo de remediação a fim de garantir a qualidade natural desses corpos d’água.

\section{sólidos}

\section{Disposição final dos resíduos}

Das técnicas existentes para a disposição e tratamento dos resíduos sólidos urbanos, tem-se nos aterros sanitários a alternativa mais viável, tanto do ponto de vista econômico, como na adequada disposição final do lixo (Souto e Povinelli, 2005; Renou et al., 2007).

A norma ABNT-NBR 13896-1997 fixa as condições mínimas exigíveis para projeto, implantação e operação de aterros de resíduos não perigosos, de forma a garantir a proteção dos recursos hídricos superficiais e subterrâneos, bem como o meio ambiente como um todo. Um aterro sanitário desenvolve-se com base nas seguintes premissas (ABNT, 1997):

- A área de disposição deverá ser recoberta por revestimento de base, composto por camadas de drenagem e impermeabilização;

- O resíduo sólido depositado deverá ser coberto diariamente por uma camada de solo, com uma espessura aproximadamente de $0,20 \mathrm{~m}$;
- O aterro deverá ser construído em células, com altura de até $5 \mathrm{~m}$;

- Deverá conter um sistema de drenagem e coleta de lixiviado e biogás instalado na base das células; e

- O topo do aterro deverá ser impermeabilizado ou possuir uma cobertura final, composto por camadas de drenagem e solo e um sistema de drenagem superficial, constituído de canaletas e escadas d'água no perímetro do aterro como um todo.

Do ponto de vista operacional, de acordo com Zveibil (2001), um aterro sanitário deve conter necessariamente as seguintes unidades:

- Unidades operacionais: células de lixo domiciliar e células de lixo hospitalar; impermeabilização de fundo (obrigatória) e superior (opcional); sistema de coleta e tratamento dos líquidos percolados (lixiviado); sistema de coleta e queima (ou beneficiamento) do biogás; sistema de drenagem e afastamento das águas pluviais; sistemas de monitoramento ambiental, topográfico e geotécnico; pátio de estocagem de materiais.

- Unidades de apoio: cerca e barreira vegetal; estradas de acesso e de serviço; balança rodoviária e sistema de controle de resíduos; guarita de entrada e prédio administrativo; oficina e borracharia.

Deve-se ressaltar, contudo, que há em uso outras formas inadequadas para a disposição final dos resíduos sólidos por aterramento, que não promovem a efetiva proteção à saúde pública e ao meio ambiente, e que ainda são largamente empregadas no Brasil. Entre essas técnicas ultrapassadas, destacam-se os lixões e os aterros controlados. 
Lixão ou vazadouro são formas de disposição final de resíduos sólidos que se caracteriza pela sua descarga sobre o solo, sem critérios técnicos e medidas de proteção ambiental ou à saúde pública; os resíduos assim lançados permanecem expostos tornando-se pontos geradores de vetores de doenças (moscas, baratas ratos etc.), além de ter seu lixiviado infiltrado no solo. Já o Aterro Controlado, possui normas técnicas para sua execução, onde se observa um maior grau de segurança para a saúde pública e minimização dos impactos ambientais; contudo, por não possuir impermeabilização da base, todo seu lixiviado, tal qual no lixão, acaba infiltrando pelo solo, podendo gerar poluição localizada e comprometer a qualidade das águas subterrâneas (Zveibil, 2001; Lanza e Carvalho, 2006). A Figura 1 ilustra essas três formas de disposição final dos resíduos sólidos.

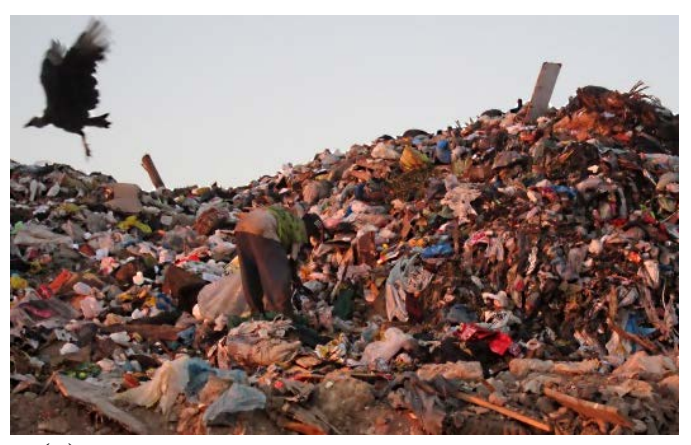

(a)

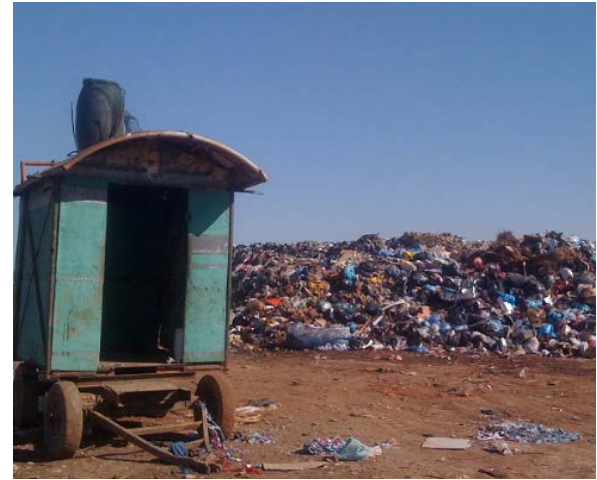

(b)

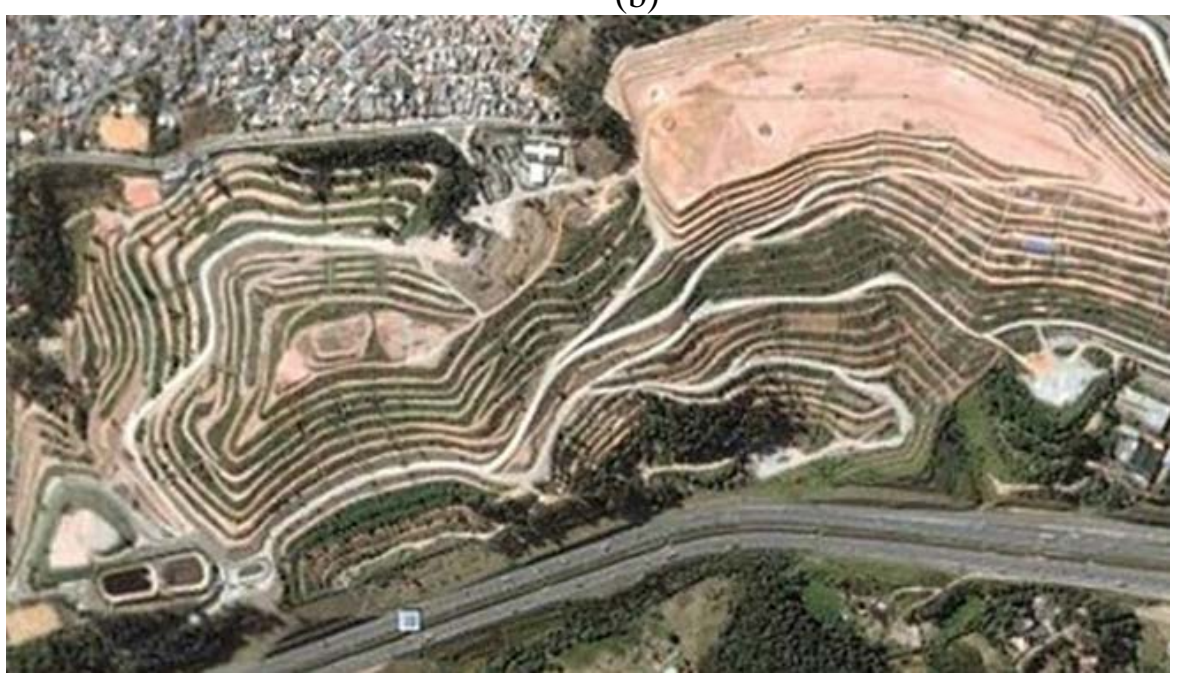

(c)

Figura 1. Na sequência: Lixão de Gramacho-RJ (a); Aterro Controlado de Goiânia (b); e Aterro Sanitário Bandeirantes (c). Fonte: (a) acervo Eduardo Pegurier; (b) acervo Instituto Brookfield; (c) acervo ambconsult.com.br.

Inerente ao uso de aterros como ferramenta de disposição dos resíduos sólidos urbanos, a geração de lixiviados contaminados permanece como uma inevitável consequência do uso de tal tecnologia (Souto e Povinelli, 2006; Wiszniowoski et al., 2006).

Lixiviados de aterro sanitário são definidos pela ABNT-NBR 8419-1992 como efluentes líquidos gerados do 
resultado da percolação de água de chuva através dos resíduos sólidos dispostos em aterros, bem como da umidade natural desses resíduos. Tais efluentes podem conter uma grande quantidade de matéria orgânica (biodegradáveis e não biodegradáveis recalcitrantes), onde os compostos húmicos constituem um importante grupo, assim como os compostos nitrogenados, metais pesados e sais inorgânicos (ABNT, 1992; Wiszniowoski et al., 2005; Moravia et al., 2006; Renou et al., 2008).

A presença desses constituintes no lixiviado, atrelado à inexistência de engenharias de controle na maioria dos aterros, combinado com o fato de que muitos aterros inadvertidamente podem ter recebido no passado, ou atualmente, resíduos perigosos e industriais, acabam por gerar a liberação de substâncias potencialmente tóxicas, as quais poderão infiltrar pelo solo até atingirem águas subterrâneas ou escoar para águas superficiais (Qasim e Chiang, 1994; Renou et al., 2008).

O lixiviado tem variabilidade de sua composição devido ao esgotamento progressivo da matéria orgânica biodegradável. Por essa razão, o elevado potencial poluidor do "lixiviado novo" vai se reduzindo paulatinamente até atingir níveis que dispensam seu tratamento, ao final de 10 anos (lixiviado velho), persistindo, contudo, uma série de outras substâncias de elevado potencial tóxico, como nitrogênio amoniacal, metais etc. (Zveibil, 2001).

É interessante ressaltar que mesmo anos após ter-se exaurida a capacidade de recebimento de resíduos sólidos em aterros, o mesmo continua a gerar continuamente o lixiviado (Bocchiglieri, 2005).

Portanto, dado sua composição e comportamento, seu contato em qualquer tempo com o solo ou corpos d'água (superficial ou subterrâneo) acarretará na introdução de poluentes e contaminantes que comprometerão não só a biota desses ambientes, mas, também, a saúde pública.

Só o Município de São Paulo produz, diariamente, 2,7 mil t de lixiviado de aterros, os quais são encaminhados para tratamento em instalações da SABESP (São Paulo, 2017).

A implantação da nova Política Nacional de Resíduos Sólidos (PNRS), por meio da Lei $\mathrm{n}^{0}$ 12.305/2010, com a proposta de uma gestão integrada e sustentável dos resíduos sólidos, vem buscando a adequação desse cenário, com o fechamento de diversos lixões e aterros controlados e sua substituição por aterros sanitários (Brasil, 2010).

De uma forma geral, a disposição final dos resíduos sólidos urbanos em aterros sanitários tem aumentado ao longo dos últimos anos no país. Enquanto no ano 2000, 17,3\% dos municípios utilizavam aterros sanitários para a destinação final, em 2008, passaram para $27,7 \%$. No entanto, cerca de metade dos 5.564 municípios brasileiros ainda dispõem em lixões, e o percentual de cidades que dispõem em aterros controlados permaneceu praticamente estagnado nos oito anos, $22,3 \%$ (2000) e $22,5 \%$ (2008) (IBGE, 2010).

A Tabela 1 apresenta alguns valores que permitem observar o destino final dos resíduos sólidos no Brasil.

Tabela 1. Destino final dos resíduos sólidos no Brasil.

\begin{tabular}{lccc}
\hline \multirow{2}{*}{ Ano } & \multicolumn{3}{c}{ Destino final dos resíduos sólidos (\%) } \\
\cline { 2 - 4 } & Lixões & Aterro controlado & Aterro sanitário \\
\hline 1989 & 88,2 & 9,6 & 1,1 \\
2000 & 72,3 & 22,3 & 17,3 \\
2008 & 50,8 & 22,5 & 27,3 \\
\hline
\end{tabular}

Fonte: PNSB - IBGE (2010). 
Nesse sentido, é possível observar o pioneirismo do Estado de São Paulo na gestão dos resíduos sólidos, ao instituir sua Política de Resíduos Sólidos, através da Lei Estadual $n^{\circ} 12.300 / 2006$, anterior, portanto, a PNRS, possuindo em seus princípios e objetivos a busca por promover a minimização dos resíduos gerados por meio de incentivos às práticas ambientalmente adequadas de reutilização, reciclagem, redução e recuperação, bem como a redução da quantidade e nocividade dos resíduos sólidos; além de buscar erradicar as práticas de disposição finais ambientalmente incorretas, tais como os lixões, aterros controlados e bota-foras priorizando o uso de aterros sanitários (São Paulo, 2006).

Por sua vez, o Município de São Paulo, implementou a PNRS através do Plano de Gestão Integrada dos Resíduos Sólidos da Cidade de São Paulo, por meio do Decreto $\mathrm{n}^{\mathrm{o}}$ 54.991/2014, destacando como principais ações a expansão da coleta seletiva e a perspectiva para o manejo diferenciado dos resíduos sólidos urbanos (orgânicos, secos e rejeitos) no horizonte de 20 anos por meio de cessões de unidades composteiras, processamento mecanizados, apoio e incentivo às cooperativas de sucateiros e catadores, definição da logística reversa de embalagens e ecoparques de segregação para reciclagem; além do compromisso com a redução das emissões de gases de efeito estufa (São Paulo, 2016).

Com o intuito de contextualizar essa mudança de cenário, a Figura 2 apresenta o mapa da Companhia Ambiental do Estado de São Paulo (CETESB) que ilustra, com o Índice de Qualidade de Aterros (IQA), a evolução da regulamentação feita pelos municípios de aterros sanitários do estado.

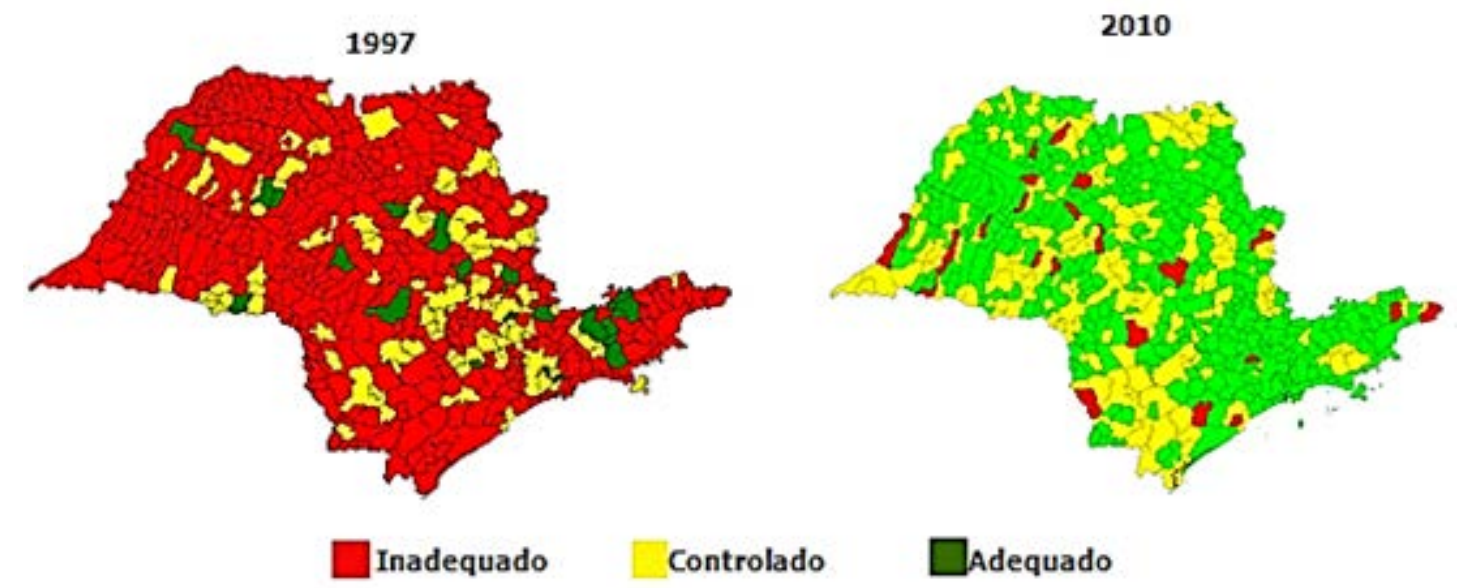

Figura 2. Índice de qualidade de aterros no Estado de São Paulo - 1997 e 2010. Fonte: CETESB (2016).

Contudo, mesmo diante desse cenário otimista, levando-se em conta o passado recente com o emprego de técnicas inadequadas para correta destinação final dos resíduos, torna-se importante avaliar o potencial poluidor ainda existente, uma vez que, como já mencionado, mesmo com a interrupção do funcionamento de aterros controlados e lixões, os mesmos permanecerão com um passivo ambiental na forma de geração do lixiviado, o qual, em função da estrutura precária, não é devidamente coletado e tratado. 


\section{Material e método}

Após o levantamento dos aterros desativados no município de São Paulo, foi utilizado o software QGIS 2.14, programa de Sistema de Informação Geográfica com código aberto, para elaboração do mapa da distribuição dos mesmos.

Utilizou-se a extensão PostGis, igualmente gratuita e de código fonte livre, para criar um banco de dados com suporte a dados geográficos e feita a inclusão dos dados referente aos aterros desativados. Sua construção permite o armazenamento e gerenciamento de banco de dados geométricos e espaciais, com o uso de objetos GIS (Sistemas de Informação Geográfica), além de calcular distâncias entre posições de latitude e longitude.

Os dados referentes às classes dos rios utilizados são da CETESB, disponível no site. Também foram utilizados dados referentes aos aterros, bota-foras e lixões disponíveis no site de Mapa Digital da Cidade de São Paulo (GeoSampa) (São Paulo, 2016).

A delimitação do buffer para avaliar o entorno do aterro foi feita com base na Portaria MINTER n ${ }^{\circ} 124 / 1980$, que estabelece como norma que "quaisquer indústrias potencialmente poluidoras, bem como as construções ou estruturas que armazenam substâncias capazes de causar poluição hídrica, devem ficar localizadas a uma distância mínima de 200 (duzentos) metros das coleções hídricas ou cursos d'água mais próximos” (MINTER, 1980).

A partir desse banco de dados e área delimitada, foi possível cruzar as informações e obter pontos de interesse, onde a presença do local de potencial poluição - aqui representado pelo aterro desativado - fora alocado dentro do mapa hidrográfico de sua área, sendo avaliado se tal proximidade efetivaria a possível influência pelo lixiviado produzido.

\section{Resultados e discussão}

\section{Localização dos aterros controlados desativados em São Paulo \\ Até 1974, o Município de São Paulo só possuía como forma de disposição}

final dos resíduos os "lixões” ou "vazadouros" (sem considerar os incineradores e a usina de compostagem), os quais foram substituídos por oito aterros. Estes aterros eram operados por empreiteiras, funcionando até 1978, não se configurando como aterros sanitários, e sim como aterros controlados. Sendo eles Lauzane Paulista (1974), Jardim Damasceno (1975), Vila São Francisco (1976), Carandiru (1977), Pedreira City (1977), Engenheiro Goulart (1975), Raposo Tavares (1975) e Pedreira Itapuí (1978) (Leite, 2005; Leo, 2006).

Na década de 1970, através do LIMPURB (Departamento de Limpeza Urbana), a Prefeitura de São Paulo começou a operar os aterros de Santo Amaro (1976), Vila Albertina (1977), Sapopemba (1979), Bandeirantes (1979), Jacuí (1980), São Mateus (1984), Inertes Itatinga (1990), São João (1992) e Inertes de Itaquera (1999) (Leite, 2005).

Atualmente, encontram-se em operação o Aterro Sanitário Centro de Disposição de Resíduos (CDR) Pedreira, com início de funcionamento em 2000, e o Aterro Sanitário Central de Tratamento de Resíduos Leste (CTL), com início de operação em 2010, além de dois aterros fora do município que são utilizados para a disposição dos resíduos, localizados nos Municípios de Caieiras e de Guarulhos (São Paulo, 2016; Cavalcante, 2014). A Tabela 2 apresenta a exata localização desses aterros no Município de São Paulo.

Georreferenciamento dos aterros no Município de São Paulo

As Figuras de 3 a 5 apresentam as geolocalizações dos aterros identificados, bem como a delimitação do buffer de 200 $\mathrm{m}$ e as condições do entorno no que tange a presença de algum corpo hídrico.

De acordo com os dados processados, todos os aterros desativados estão a menos de $200 \mathrm{~m}$ de distâncias de corpos d'água superficiais e, em quase todos os casos, os aterros estão próximos de cursos d'água Classe 4, destinadas à navegação e à harmonia paisagística (Brasil, 2005).

O Aterro Inertes Itatinga está próximo de cursos d'água Classe 2, 
destinados ao abastecimento e consumo humano e à proteção da comunidade aquática, e o Aterro Bandeirantes está próximo de cursos d'água Classe 3 , que por sua vez, destina-se ao abastecimento humano, irrigação de culturas arbóreas, cerealíferas e forrageiras, à pesca amadora, à recreação de contato secundário e à dessedentação de animais (Brasil, 2005).

Cada aterro contém suas próprias questões socioambientais, histórico de tipo de resíduos e diversos fatores para analisar em seu trajeto de operação; pressupõe-se que, em função da inexistência de medidas de contenção do lixiviado, todos os aterros desativados possam causar ou tenham causado algum tipo de impacto aos cursos d'água em seu entorno.

Para que a existência da contaminação seja confirmada, faz-se necessária a realização de uma completa investigação de campo e laboratorial, com o intuito de caracterizar e quantificar o contaminante e/ou substância poluidora (Mondelli et al., 2016).

Tabela 2. Relação dos aterros desativados no Município de São Paulo.

\begin{tabular}{|l|l|l|}
\hline Aterro & \multicolumn{1}{c|}{ Localização } & \multicolumn{1}{c|}{ Tipo } \\
\hline Lauzane Paulista & Av. Dr. Francisco Raniere 834 & Aterro \\
\hline Jardim Damasceno & Rua Feliciano Malaia, $\mathrm{n}^{\circ} 500$ & Aterro \\
\hline Eng. Goulart & Parque Ecológico do Tietê & Aterro \\
\hline Raposo Tavares & Rodovia Raposo Tavares, km 14,5 & Aterro \\
\hline Santo Amaro & Avenida Miguel Yunes, 343 & Aterro sanitário \\
\hline Vila São Francisco & Avenida Imperador com Avenida Água Haia & Aterro \\
\hline Vila Albertina & Rua José Aguirre de Camargo, $\mathrm{n}^{\circ}$ 400 & Aterro sanitário \\
\hline Carandiru & Avenida Zaki Narchi & Aterro \\
\hline Pedreira Itapuí & Avenida Líder com Rua Agostinho de Faria & Aterro \\
\hline Pedreira City & Rua Caminho do Engenho, s/n ${ }^{\circ}$ & Aterro \\
\hline Sapobemba & Avenida Sapopemba, $\mathrm{n}^{\circ}$ 26351 & Aterro sanitário \\
\hline Vila Jacuí & Avenida Mimo do Vênus & Aterro sanitário \\
\hline São Mateus & Marginal esquerda do córrego Fazenda Velha & Aterro sanitário \\
\hline Bandeirantes & Rodovia dos Bandeirantes, km 26,5 & Aterro sanitário \\
\hline Inertes Itatinga & Rua Aniquis & Aterro inerte \\
\hline Sítio São João & Estrada Sapopemba, km 33 & Aterro sanitário \\
\hline Inertes Itaquera & Avenida Itaquera, 5889 & Aterro inerte \\
\hline
\end{tabular}

Fonte: Adaptado de Leite (2005), Leo (2006) e São Paulo (2016). 

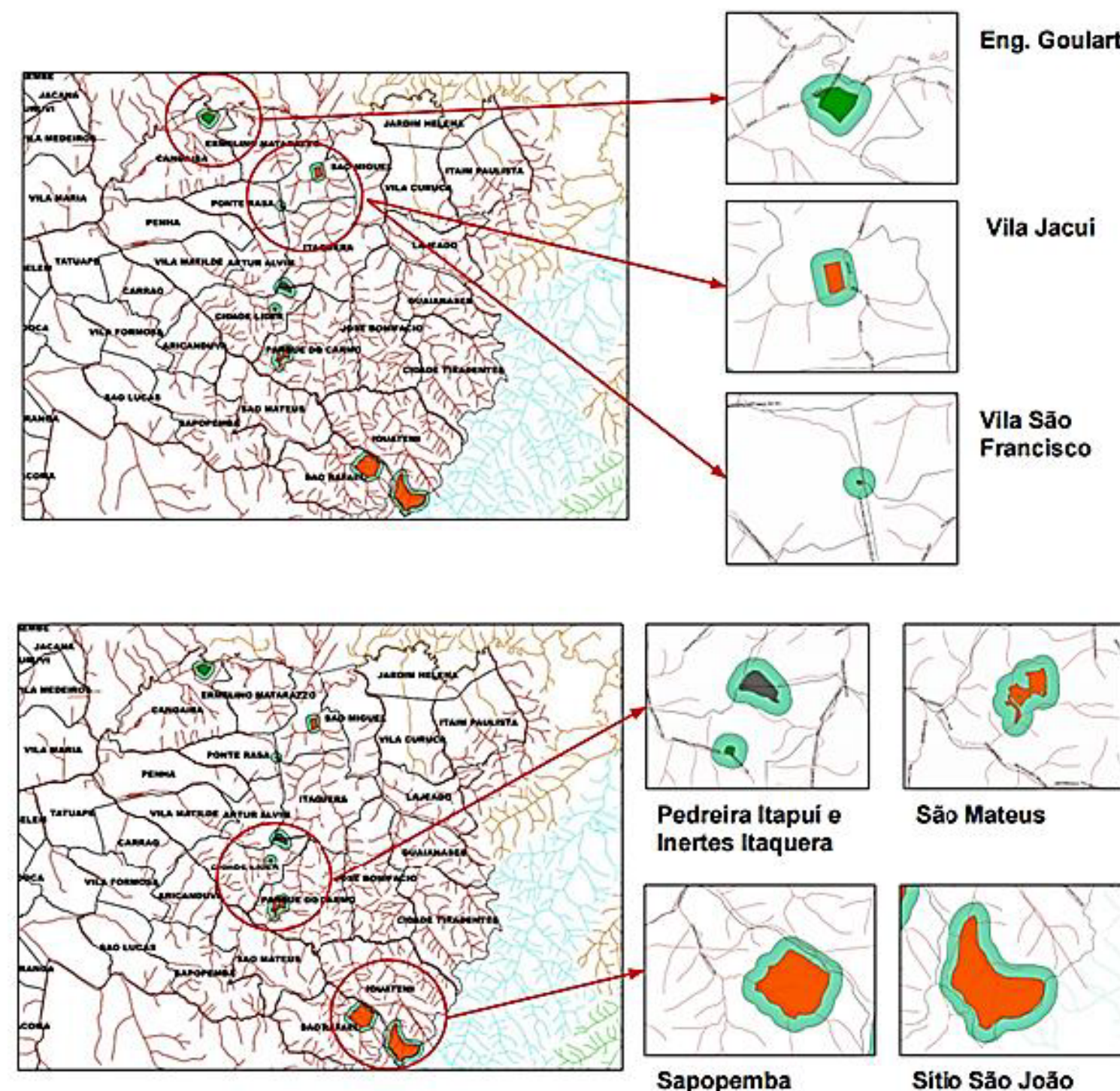

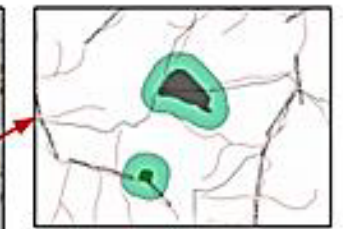

Pedreira Itapui e Inertes Itaquera

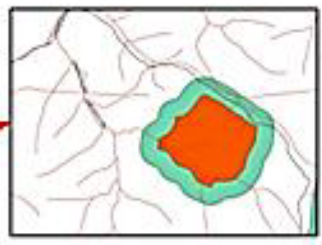

Sapopemba

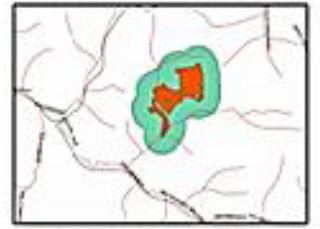

Săo Mateus

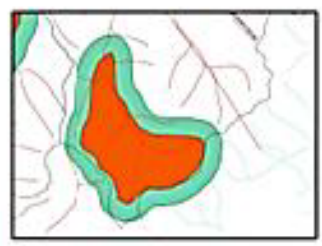

Sitio Săo Joăo

Figura 3. Distribuição dos aterros na Zona Leste do Município de São Paulo. Escalas: Mapa 1:120.000. 


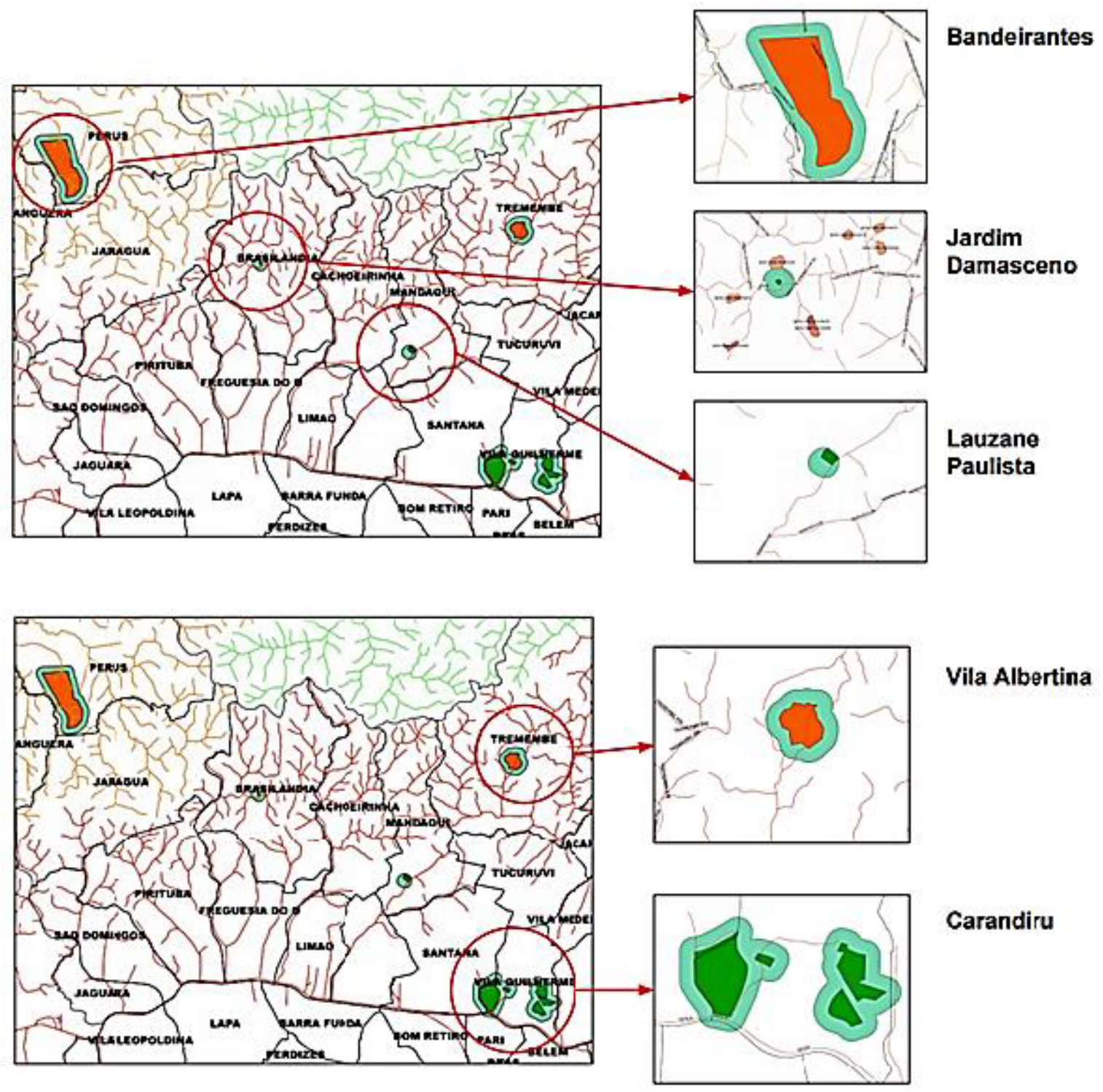

Figura 4. Distribuição dos aterros na Zona Norte/Oeste do Município de São Paulo. Escalas: Mapa 1:90.000, Aterro 1:15.000. 


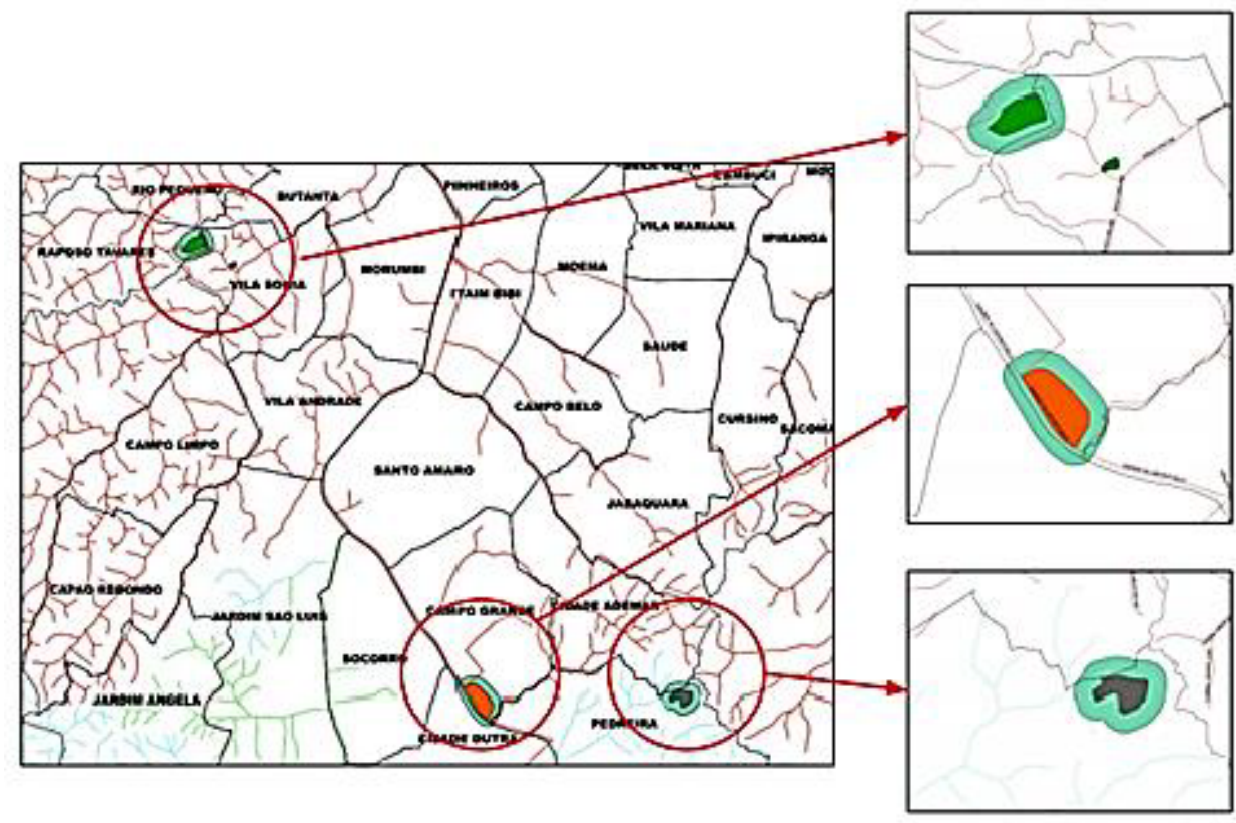

Raposo Tavares e Pedreira City

Figura 5. Distribuição dos aterros na Zona Oeste/Sul do Município de São Paulo. Escalas: Mapa 1:90.000, Aterro 1:15.000.

Aparentemente, não há nenhum programa de monitoramento da atividade desses aterros desativados, tão pouco, dos corpos d’água que lhes estão próximas.

Os principais cursos d'água que podem estar recebendo os lixiviados são:

\section{- Aterros Zona Leste (Figura 3)}

Eng. Goulart: Rio Tietê

Vila Jacui: Rio Jacu e Rio Tietê

Vila São Francisco: Córrego Ponte Rasa, Adjacente Córrego Tiquatira e Rio Tietê

Inertes Itaquera: Rio Verde (canalizado), Rio Jacu e Rio Tietê

Pedreira Itapuí: Afluente ao Córrego Guaiauna e Rio Tietê

São Mateus: Afluente ao Rio Aricanduva e Rio Tietê

Sapopemba: Afluente ao Córrego Caguaçu, Rio Aricanduva e Rio Tietê

Sítio São João: Afluente ao Córrego do Limoeiro, Rio Aricanduva e Rio Tietê
- Aterros Zona Norte/Oeste (Figura 4)

Carandiru: Rio Tietê

Vila Albertina: Ribeirão Tremembé, Rio Piqueri, Rio Cabuçu de Cima e Rio Tiête.

Lauzane: Córrego Mandaqui e Rio Tietê

Jardim Damasceno: Afluente, Cabuçu de baixo e Rio Tietê

Bandeirante: Afluente e Rio Juqueri (Classe 3)

- Aterros Zona Oeste/Sul (Figura 5)

Raposo Tavares: Ribeirão Jaguaré, Ribeirão Pirajuçara e Rio Tietê

Pedreira City: Ribeirão Pirajuçara e Rio Tietê

Santo Amaro: Rio Jurubatuba, Rio Pinheiros e Rio Tietê

Inertes Itatinga: Afluente e Represa Billings (Classe 2) 


\section{Conclusão}

Deve-se ressaltar que o presente estudo não teve por premissa evidenciar um nexo explícito entre a geolocalização de aterros desativados e a consequente poluição de cursos d’água em seu entorno, uma vez que, para tanto, fazer-se-iam necessários uma campanha de monitoramento da geração de lixiviado por parte deles, bem como a determinação da infiltração desses lixiviados até lençóis freáticos ou em tais cursos superficiais.

Fato é que, em função das peculiaridades estruturais de um aterro controlado e a inevitável geração contínua de lixiviado mesmo após a interrupção do funcionamento, a inexistência de um controle e monitoria abre espaço para uma forte especulação de que, de alguma forma, esses cursos d’água citados recebem ou receberam contribuição dessa carga poluidora.

Isto posto, a principal conclusão que esse trabalho pode oferecer é que, por mais que o governo de São Paulo seja um dos mais empenhados em se adequar frente à nova política nacional de resíduos sólidos urbanos, há um passivo histórico que persiste e que pode ser objeto de perturbação da qualidade dos corpos d'água já tão impactados e deteriorados nesse Estado, demandado, portanto, ações de monitoramento e recuperação ambiental dos cursos d'água eventualmente impactados por essa prática.

\section{Declaração de conflito de interesses}

Os autores declaram não haver conflito de interesses.

\section{Referências}

ABNT - Associação Brasileira de Normas Técnicas. ABNT-NBR 8419 - Apresentação de projetos de aterros sanitários de resíduos sólidos urbanos. Rio de Janeiro: ABNT, 1992.

ABNT - Associação Brasileira de Normas Técnicas. ABNT-NBR 13896 - Aterros de resíduos não perigosos: critérios para projetos, implantação e operação. Rio de Janeiro: ABNT, 1997.
ABRELPE - Associação Brasileira de Empresas de Limpeza Pública e Resíduos Especiais. Panorama do Resíduo Sólido no Brasil. 2014. Disponível em: <http://www.abrelpe.org.br/ Panorama/panorama2014.pdf $>$. Acesso em: 15 out. 2016.

Bocchiglieri, M. M. A influência do recebimento de chorume dos aterros sanitários da Região Metropolitana de São Paulo nas estações de tratamento de esgotos do sistema integrado. São Paulo: Faculdade de Saúde Pública, Universidade de São Paulo, 2005. (Dissertação de mestrado).

Boscov, M. E. G. Geotecnia ambiental. São Paulo: Oficina de Textos, 2008.

Brasil. Lei $\mathbf{n}^{0}$ 12.305, de 2 de agosto de 2010. Institui a Política Nacional de Resíduos Sólidos; altera a Lei $\mathrm{n}^{\circ}$ 9.605, de 12 de fevereiro de 1998; e dá outras providências. Disponível em: <http://www.planalto.gov.br/ccivil_03/_ato2007 -2010/2010/lei/l12305.htm>. Acesso em: 25 abr. 2017.

Brasil. Resolução CONAMA no ${ }^{\mathbf{3}}$ 35, de 17 de março de 2005. Dispõe sobre a classificação dos corpos de água e diretrizes ambientais para o enquadramento, bem como estabelece as condições e padrões de lançamento de efluentes, e dá outras providências. Disponível em: <http://www.mma.gov.br/port/conama/legiabre. cfm?codlegi=459>. Acesso em: 25 abr. 2017.

Cameron, K. C.; Di, H. J.; Mclaren, R. G. Is soil an appropriate dumping ground for our wastes? Australian Journal of Soil Research, v. 35, n. 5, p. 995-1036, 1997. https://doi.org/10.1071/S96099

Cavalcante, S. S. S. Geração de lixiviados de aterros sanitários na Região Metropolitana de São Paulo: histórico e perspectivas. São Paulo: Faculdade de Saúde Pública, Universidade de São Paulo, 2014. (Dissertação de mestrado).

CETESB - Companhia Ambiental do Estado de São Paulo. Enquadramento dos Corpos Hídricos - Arquivos digitais. Disponível em: $<$ http://aguasinteriores.cetesb.sp.gov.br/enquadr amento-dos-corpos-hidricos-arquivos-digitais/> . Acesso em: 17 out. 2016.

CETESB - Companhia Ambiental do Estado de São Paulo. Resíduos sólidos. Índice de qualidade dos aterros. Disponível em: $<$ http://residuossolidos.cetesb.sp.gov.br/residuos -solidos/residuos-urbanos-saude-construcaocivil/introducao/>. Acesso em: 25 abr. 2017.

Gorayeb, A. Análise integrada da paisagem na Bacia Hidrográfica do Rio Caeté Amazônia Oriental - Brasil. Rio Claro: 
Universidade Estadual Paulista, 2008. (Tese de Doutorado). Disponível em: $<$ http://repositorio.unesp.br/bitstream/handle/11 449/100074/gorayeb_a_dr_rcla.pdf>. Acesso em: 18 out. 2016.

Gouveia, N.; Prado, R. R. Riscos à saúde em áreas próximas a aterros de resíduos sólidos urbanos. Rev. Saúde Pública, v. 44, n. 5, p. 859-866, 2010. http://dx.doi.org/10.1590/ S0034-89102010005000029

Guimarães, L. T. Utilização do Sistema de Informação Geográfica (SIG) para identificação de áreas potenciais para disposição de resíduos na Bdo Paquequer, Município de Teresópolis - RJ. Rio de Janeiro: Universidade Federal do Rio de Janeiro, 2000. (Dissertação de Mestrado).

IBGE - Instituto Brasileiro de Geografia e Estatística. Atlas de saneamento. Rio de Janeiro: IBGE, 2011. Disponível em: <http://biblioteca.ibge.gov.br/visualizacao/livro s/liv53096_cap9.pdf >. Acesso em: 17 out. 2016. IBGE - Instituto Brasileiro de Geografia e Estatística. Cidades, infográficos, São Paulo, São Paulo. Dados gerais. Disponível em: $<$ http://cidades.ibge.gov.br/painel/painel.php?co dmun=355030 $>$. Acesso em: 17 out. 2016.

IBGE - Instituto Brasileiro de Geografia e Estatística. Pesquisa Nacional de Saneamento Básico 2008. Rio de Janeiro: IBGE, 2010.

IBGE - Instituto Brasileiro de Geografia e Estatística. Pesquisa Nacional de Saneamento Básico. Rio de Janeiro: IBGE, 2008. Disponível em:

<http://www.ibge.gov.br/home/presidencia/noti cias/imprensa/ppts/0000000105.pdf>. Acesso em: 17 out. 2016.

Jacobi, P. R.; Bensen, G. R. Gestão de resíduos sólidos em São Paulo: desafios da sustentabilidade. Estudos Avançados, v. 25, n. 71, p. 135-158, 2011. http://dx.doi.org/10.1590/S010340142011000100010

Lanza, V. C.; Carvalho, A. L. Orientações básicas para operação de aterro sanitário. Belo Horizonte: Fundação Estadual do Meio Ambiente, 2006.

Leite, T. M. C. Entraves espaciais: Brownfields caracterizados por aterros de resíduos sólidos desativados no Município de São Paulo/SP. Rio Claro: Universidade Estadual Paulista, 2005. (Tese de Doutorado). Disponível em: <http://repositorio.unesp.br/bitstream/ handle/11449/104385/leite_tmc_dr_rcla.pdf>.

Acesso em: 17 out. 2016.
Leo, O. C. O lugar do lixo na Cidade de São Paulo, a gestão territorial e a contribuição geográfica. São Paulo: Faculdade de Filosofia, Letras e Ciências Humanas, Universidade de São Paulo, 2006. (Dissertação de mestrado).

MINTER - Ministério de Estado do Interior. Portaria $n^{0}$ 124, de 20 de agosto de 1980. Disponível em: <http://www.oads.org.br/ leis/3426.pdf > . Acesso em: 17 out. 2016.

Mondelli, G.; Giacheti, H. L.; Hamada, J. Avaliação da contaminação no entorno do aterro de resíduos sólidos urbanos com base em resultados de poços de monitoramento. Revista Engenharia Sanitária e Ambiental, v. 21, n. 1, p. 169-182, 2016. https://dx.doi.org/10.1590/ S1413-41520201600100120706

Moravia, W. G.; Amaral, M. C. S.; Ferreira, C. F. A.; Lange, L. C.; Martins, L. K. Estudo de diferentes métodos de partida de sistemas de tratamento aeróbio para lixiviados de aterro sanitário estabilizado em escala de laboratório. Anais do $24^{\circ}$ Congresso Brasileiro de Engenharia Sanitária e Ambiental, 2006.

Muñoz, S. I. S. Impacto ambiental na área do aterro sanitário e incinerador de resíduos sólidos de Ribeirão Preto, SP: avaliação dos níveis de metais pesados. Ribeirão Preto: Escola de Enfermagem de Ribeirão Preto, Universidade de São Paulo, 2002. (Tese de doutorado).

Qasim, S. R; Chiang, W. Sanittary landifill leachate: generation, control and treatment. Pensilvânia, EUA: Technomic Publication, 1994.

Ranzi, B. D. Tratamento de lixiviados de aterro sanitário por evaporação natural com painéis: estudo em escala piloto. Florianópolis: Universidade Federal de Santa Catarina, 2009. (Dissertação de mestrado).

Renou, S; Givaudan, J. G.; Poulain, S.; Dirassouyan, F.; Moulin, P. Landifill leachate treatment: review and opportunity. Journal of Hazardous Materials, v. 150, n. 3, p. 468-493, 2007. https://doi.org/10.1016/j.jhazmat.2007. 09.077

Samuel-Rosa, A.; Dalmolin, R. S.; Copetti, A. C. C. A poluição causada por aterros de resíduos sólidos urbanos sobre os recursos hídricos. Ciência e Natura, v. 34, n. 1, p. 107118, 2012. http://dx.doi.org/10.5902/2179460X 9357

São Paulo. Governo do Estado de São Paulo. Lei $n^{\circ}$ 12.300, de 16 de março de 2006. Institui a Política Estadual de Resíduos Sólidos e define princípios e diretrizes. Disponível em: <http://www.saneamento.sp.gov.br/Arquivos/ Decretos/Arquivo 3 - Politica estadual de RS - 
2006_Lei_12300.pdf>. Acesso em: 16 out. 2016.

São Paulo. Prefeitura de São Paulo. Portal da Prefeitura de São Paulo. Disponível em: $<$ http://www.prefeitura.sp.gov.br>. Acesso em: 25 abr. 2016.

São Paulo. Prefeitura do Município de São Paulo. Mapa Digital da Cidade de São Paulo (GeoSampa). Disponível em: $<$ http://geosampa.prefeitura.sp.gov.br/PaginasP ublicas/_SBC.aspx>. Acesso em: 16 out. 2016.

São Paulo. Prefeitura do Município de São Paulo. Plano de Gestão Integrada Resíduos Sólidos da Cidade de São Paulo (PGIRS). 2014. Disponível em: <http://www.prefeitura.sp.gov.br/cidade/secreta rias/upload/servicos/arquivos/PGIRS2014.pdf>. Acesso em 16 out. 2016.

Souto, G. D. B.; Povinelli, J. Características do lixiviado de aterros sanitários no Brasil. Anais do $24^{\circ}$ Congresso Brasileiro de Engenharia Sanitária e Ambiental, referência III-040, 2005.

Stuermer, M. M.; Brocaneli, P. F.; Vieira, M. E. M. Os aterros sanitários desativados e o sistema de áreas verdes da Cidade de São Paulo: possibilidade de integração. Revista LABVERDE, n. 2, p. 11-29, 2011. https://dx.doi.org/10.11606/issn.21792275.v0i2p11-29

Wiszniowski, J.; Robert, D.; Surmacz-Gorska, J.; Miksch, K.; Weber, J. V. Landifill leachate treatment methods: a review. Environ. Chem. Lett., $\quad$ v. 4, n. 1, p. 51-61, 2006. https://dx.doi.org/10.1007/s10311-005-0016-z

Zveibil, V. Z. (Coord.). Manual de gerenciamento integrado de resíduos sólidos. Rio de Janeiro: IBAMA, 2001. Disponível em: $<$ http://www.resol.com.br/cartilha4/manual.pdf $>$. Acesso em: 17 out. 2016. 